\title{
Game Jam as Feminist Methodology: The Affective Labours of Intervention in the Ludic Economy
}

\author{
ABSTRACT: \\ This article examines the evidenced and the potential impact of all- female games jams as \\ an element within a feminist interventionist approach to improving women's equal \\ participation within the ludic economies of the games industry. The article examines two \\ specific projects - a single site 24-hour event that took place in 2012 and a restaging of \\ the format 4 years later across 5 different sites in the UK. These two case studies offer \\ two critical contributions to the ongoing research regarding the wider challenges of \\ diversifying games design, games development and games culture more generally. The \\ first is a consideration of the range of labours - free, hopeful and affective - that underpin \\ these endeavours and provide a significant contribution in general to the ludic economy. \\ The second is valuable evidence of the impact and ongoing validity of these all-female \\ initiatives as an effective and transformative methodology for feminist intervention.
}

Keywords: game jam, games industry, feminism, affective labour, methodology Article:

The purpose of the article is to examine the possibilities and limitations of an all-female game jam format as a component within a range of feminist interventions into the ludic economies of the games industry. The two case studies that form the focus of this examination are each part of a wider international collaboration that has spanned more 
than ten years. The first all-female game jam (October 2012) was a companion project to a Social Sciences and Humanities Research Council of Canada (SSHRC) networking grant (2011 - 2013) and the second more recent (October 2016) event is a project funded by a partnership grant emerging from this earlier collaboration - ReFiguring Innovation in Games Design (ReFIG) - which is a 5 year grant running from 2015 - 2020 that aims to intervene in industry and maker practices with a view to promoting diversity in game development whilst also improving the conditions for all workers.

In what follows I will be situating a specific set of practices (the organisation and delivery of all-female game jams) within a wider framework of feminist interventionist and activist work in support of women's participation in the games industry. I examine two such events - a single site event that took place in 2012 (critically before the explosion of gamergate $^{I}$ ) and a restaging of the format 4 years later across 5 different sites in the UK in order to revitalise this activity in this national context and to identify potential follow-on activity that might secure greater clarity and sustainability of the impacts of these kinds of interventions.

A game jam is an informal creative space, time-bound, resource-bound, task driven event through which to create a game; they have been around for more than 15 years and are used as a rapid prototyping strategy to deliver innovation and new ideas to the sector. They are now a key component within the amateur, independent and more commercial sectors of the games industry as key spaces of networking and skills showcasing as well

\footnotetext{
${ }^{1}$ See Huntemann 2015 for an academic analysis of Gamergate and Lewis 2012 for a very early snapshot.
} 
as a means of skills development and community building. As such they play a very key role in the ludic economy generally. I will explore these in more detail below but before we proceed, it is worth signaling that this is a format which emulates the project driven, high pressure, precarious wider work structures of the games industry of which they are now an ever increasingly important part. They are more often than not a largely male grouping (although this will depend on the context within which they are positioned) and they are popularly represented as pizza- and beer- fuelled, highly competitive and intense activities. The wider practices that they model, couched and concealed as they are within a more playful, experimental rhetoric, requires us to approach the application or uncritical celebration of this format with a great deal of caution.

The all-female game jams under examination must be considered within a range of different critical and industrial contexts: their role as a 'hopeful', utopian, affectively rich and critical play form; their specific situation in the UK national environment; the position of games within the wider creative industries; and the context of diversity and inclusion initiatives within the cultural and creative sectors on a local and global scale.

The initiatives that underpin these case studies are dependent upon a number of factors they depend upon a wider discourse of the "case for diversity" which provides the means through which to argue for and secure minimal (often seed) funding and some institutional buy in (often in the form of providing access to space or other technical resource) to support these events. They furthermore depend upon a range of forms of 
unacknowledged and often invisible labour that enable passionate projects such as these to deliver far beyond the limitations of the official funding available.

\author{
Section 1: The Many Labours of Feminist Intervention within the Ludic Economy \\ In this analysis of these game jam events, their organisation and their impacts I am \\ responding to the challenge laid down by Harvey and Shepherd in 'When Passion is not \\ enough' (2016) and the work of others who have argued for a need to recognise, evaluate \\ and (in some cases) better reward 'affective' labour in feminist interventionist /action \\ research (Oksala, 2016). \\ To do so, I will be treating these all-female game jams as affective projects which are \\ dependent upon a specific form of feminist game design practices and labour in their \\ implementation:
}

Affective labor is theorized as an important subcategory of immaterial labor. It is the labor of human contact and interaction, which involves the production and manipulation of affects. Its "products" are relationships and emotional responses: "a feeling of ease, well-being, satisfaction, excitement or passion" (Hardt and Negri 2004, 96).

\begin{abstract}
Affective labor is thus immaterial in the sense that its products are intangible, even though it is usually corporeal and mixes with material forms of labor. (Oksala: 284)
\end{abstract}


Oksala outlines the predominant conceptualisation of affective labour that has proven to be critical in examining highly-gendered forms of often invisible and unrecognised work. I want to extend this definition of affective labour beyond from the idea of producing affects to one which captures the extent to which these projects are themselves dependent upon labour which is material of course but also 'affective' in that it depends upon emotional and imaginative investments. Oksala, whilst highlighting the importance of this conceptual framework, problematizes the ways in which a theorisation of affective labour might lack precision as a means to fully recognise the complexity of labour in feminist activist projects:

$[B] y$ treating very different kinds of experiences, activities, and services as the same, the notion ends up obscuring the forms of oppression and exploitation at stake and leaves feminists unable to formulate concrete proposals for forms of resistance against them. (Oksala 288)

This suggests that greater analytical and conceptual insight could be achieved if the critical foregrounding and excavation of affective labour was accompanied by much greater direct analysis of the complexities of the operations of affect within particular events, activities and initiatives.

In this article, I am arguing that a valuable way of extending the impact of illuminating affective labour is to 'flesh out' this work, to return it to the subjects in play in the initiatives I am considering. This (re)turn to the subject allows for greater complexity and richness in the detail of the affects that are activating and activated through these projects 
from conception, to delivery, to reflection. To address the challenge indicated by Oksala, I examine in some detail the way that affect is the animating force in this activist and interventionist initiative. I argue understanding the operations of a hopeful affect as 'anticipatory' is critical in relation to the examination of feminist activism in general and this particular project more specifically. For the feminist researching subject, for instance, it is the hope of a 'different future' that animates and sustains the often deadening but vitally critical, work of applying for funding to support feminist work ${ }^{2}$

Two other approaches to examining labours at play in a specifically creative field such as games are relevant here. While neither of these specifically draw on the theories underlying affective labour, they are connected in that both indicate a future-oriented emotional or passionate investment. These are Tiziana Terranova's conceptualisation of free labour and Kuehn \& Corrigan's analysis of hope labour.

Terranova's concept "implies a privatization of the wealth produced by free labor that takes the shape of an impoverishment of potential users' appropriation of the fruits of such labor." (Terranova, 2012: 103) This concept of free labour has been usefully applied to other forms of digital labour ${ }^{3}$ particularly as it relates to processes through which the wider forces within the creative economy ensure "the extraction of value out of continuous, updateable work, [that] is extremely labor-intensive." (Terranova, 2012: 92). Terranova's influential analysis of the exploitation of this freely-given labour within the

\footnotetext{
${ }^{2}$ Coleman 2016, Adams et al 2009, Bergold and Thomas 2012

${ }^{3}$ For a recent application see Kylie Jarrett's The Digital Housewife 2015
} 
creative economy is the critical backdrop to these initiatives and an attention to the political dimension of her insight is key to a reflexive approach within feminist interventionist work in relation to the games industry. Coupled with the precarity of work in the creative sector as a whole and the dire working conditions and expectations of labour within the games industry in general, we have a potentially highly toxic environment which we might more obviously choose to caution against rather than promote (Conor, Gill \& Taylor 2015). It is the ongoing 'hope' for, 'anticipation of' and belief in the possibility of a transformed games design, games development and games culture that underpins and critically sustains these projects through these messy contradictions. $^{4}$

The framework of 'hope labour' refers to the positive engagement in very low paid or indeed unpaid work which may provide additional experience of access to new networks and connections in the anticipation of gainful employment in the future. (Kuehn and Corrigan 2013:10) Within Kuehn and Corrigan's analysis of a particular form of this unpaid labour (the provision of online content), they note:

$[\mathrm{H}]$ ope labor is ideologically positioned as a meritocratic investment in one's employment prospects. Whether social production leads to a future career or not, hope labor's work in the present is already done. Conducive to the new spirit of capitalism, social media firms have

\footnotetext{
${ }^{4}$ Harvey and Fisher 2016 have also pointed to this intrinsic challenge in any feminist work supporting women's access to the games industry. The wider REFIG project has four clear lines of priority through which to identify and address these distinct but related territories of exclusion and problematic practice.
} 


$$
\begin{aligned}
& \text { already effectively valorized this form of leisure - and hope-for the } \\
& \text { purposes of capital accumulation. (21) }
\end{aligned}
$$

\author{
Hope labour's distinctiveness compared to other forms of free labour is the temporality of \\ the anticipatory, future-oriented relation between current experience and a potential \\ aspirational outcome (Kuehn \& Corrigan, 2013:21, see also Duffy, 2015 for a further \\ analysis of aspirational labour in YouTube beauty videos).
}

\begin{abstract}
Within games production cultures these are already familiar forms of labour, the freely given and the hopeful have always been evident in the realm of 'bedroom' production from the very origin of games to our contemporary moment of the veritable explosion of amateur creativity across a range of platforms.
\end{abstract}
Drawing on these frameworks, I argue there are four transecting forms of affectual labour within the ludic economies of feminist interventionist games research:

1. The hopeful labour of the feminist academics, researchers, and activists, frequently though not always in secure employment but with a commitment to improving access for others within their field or in relation to their particular object of study. They are not necessarily individually experiencing the exigencies of the issues they are tackling but their hopeful activism depends upon a vision of a collective and better future. They will often work willingly beyond their contracts to deliver additional emotional labour to their context specific 'intervention'. 
2. The hopeful labour of the participants who are future-oriented, prospective, committed, and energetic as Kuehn and Corrigan have described (2013).

3. The free labour of the participants which includes creative practical labour in their skills development and maintenance of their online profiles. Their unpaid participation in initiatives such as these game jams is precisely the 'freely given' activity that Terranova describes. In the absence of structures of support and development within the industry for these participants, they must take individual responsibility for their self-improvement.

4. The affective labour of the volunteers and mentors, who are not only providing their expertise in support of the event but in setting the tone and mood for these activities. This includes allaying anxiety, engendering confidence and helping to maintain a positive and generous energy at the event.

\section{Section 2: Games and the Mobility of Creative Labour}

The initiatives that this article describes have a relationship with a much broader landscape of creative practice. Although these game jams are small-scale, localised and temporally-bounded events, they are a node within a topology of monetised and highly valorised activities beyond the realm of games alone. The 'talents' and labour that underpin the games industry is often situated within a highly mobile workforce, migrating across contexts beyond those of games alone - designers, animators, artists, researchers, and coders are part of a wider cultural precariat that follow the funding and freelance work opportunities, often from project to project. Scholarship that directly engages in the sociological, economic and discursive analysis of this industry is relatively scant in 
comparison to that on other industrial practices and domains - although there are highly influential analyses of creative industries \& labour (such as Gill, 2000, 2012; Conor, Gill \& Taylor, 2015; Hesmondhalgh, 2010) and within the games industry - Banks and Deuze 2009; Kerr, 2015, Preston et al. 2016).

Historically, there have been few systematic studies of the experiences of women working in the games industry. Rosalind Gill's analysis of new media freelancers is however entirely relevant to this field. Her own research has shown:

Clear divergences between men's and women's experiences, and they have no language to make sense of this, except in individualistic terms which inevitably construct women's relative lack of success in terms of individual failure (couldn't hack it, wasn't good enough, not committed enough, etc.) $[.].[U] 1$ timately its individualism, [...that] conceals (and renders difficult to speak of) the serious patterns of inequality that are emerging in this new field. (Gill, 2002:85-6)

Harvey and Shepherd also point to this in their study of women's participation in industry incubators in Canada - where female respondents would willingly endorse and reinforce a discourse of their own lack of skill:

Many women do not see themselves as good enough and question their abilities. They will think of all the reasons that they shouldn't participate. ... As we found in Pixelles, this lack of credibility is ventriloquized by women themselves, as they articulate their entry into design as somehow less competent through a focus on the technical 
ability needed to make a game rather than the creativity they brought to their designs. (Harvey \& Shepherd, 2016: 13)

We will see these same tendencies in the case study participants descriptions of their motivations and preconceptions about game jams below.

Gill also examines the ways in which her research respondents avoided, denied, disavowed any gendered dimension to their experience and certainly did not have any interest in or alignment with feminism or feminist goals, intentions or politics. This makes it harder to gain traction on the most appropriate means of supporting these women who have so clearly accepted, adopted and internalized this discourse of individual failure if they do not succeed.

\section{Section 3: Game Jam Ontology}

A game jam is a short intense event (usually between 48 and 72 hours) at which designers, programmers, artists, researchers and sometimes scholars come together to rapidly prototype games (including non-digital games such as board games, card games, and street games). Participants often work 'around the clock' to a specific 'theme' or challenge ${ }^{5}$. Pre-formed teams are sometimes allowed to participate but more frequently participants are encouraged to form teams with those they meet for the first time at the event. Although the format may have a much longer history, the shared naming of these

\footnotetext{
${ }^{5}$ A theme might be a single evocative word such as 'ritual' and challenges might be focused on an issue such as communicating climate change (see climategamejam.org)
} 
events as 'jams' emerged in the early $21^{\text {st }}$ century ${ }^{6}$. Game jams are now a key component within the amateur, independent and more commercial sectors of the games industry. There is now scholarship dedicated to the study of the form and 2016 saw the first dedicated academic conference. ${ }^{7}$ One of the most significant game jams now approaching its tenth year is the Global Games Jam (GGJ) - which recruits participants to sites all across the globe. In 2016 there were over 30,000 participants across more than 600 sites within 90 countries. Games design and development courses across the world regularly use the game jam format as a means of rapidly introducing students to the field whilst building the student community. ${ }^{8}$

The imposition of a strict time limit and a competitive framework are intended to foster innovative thinking, rapid problem solving, an iterative approach and the development of a strong team dynamic. They have proven to be a highly valuable method for stimulating innovation and new ideas within the games industry - again across the academic, independent and commercial boundaries.

The intensity of these activities and the widespread the perception of these as technologically-driven events coupled with the requirement to commit two days of time

\footnotetext{
${ }^{6}$ see the very recently published Cornish, Farber, Fleming and Miklasz 2017 The Game Jam Guide, ETC Press for a brief history of the evolution of our contemporary model of organized recurrent game jams from the $0^{\text {th }}$ Indie Game Jam in 2002 onwards. The publication has already sparked discussion regarding earlier examples of the form, so I expect to see this information updated in response to this publication.

${ }^{7}$ The International Conference on Game Jams, Hackathons and Game Creation Events is now an annual event. It was inaugurated at UC Berkeley, California, USA on March 13, 2016

${ }^{8}$ The format is also used in games art courses as often as it is in development or design courses - see MIT Games Lab, NYU Games Lab, LSBU, and Concordia's TAG lab, to name but a few.
} 
has contributed to their image and reality as male-dominated. GGJ has attempted to counter this in their publicity and have recently set up a diversity scholarship as well as a safer space policy as part of their guidelines to all sites.

\section{Section 4: Game Jam as Feminist Play Space - Computer games an act of production in their playing - the Game Jam an act of playing in their production}

In what follows, I examine the intentions and partial outcomes from two game jams - one in 2012 and the other in 2016. In 2012, I was awarded a small grant to adapt the game jam format to design an all-female event as an initiative to improve women's participation in games. At this time, game jams were clearly becoming a critical tool for generating participation within the games industry - to the extent that many describe these events as 'rites of passage'. Furthermore, I wanted to adapt the format sufficiently to address some of the barriers to participation which were evident in the standard form, and to allow young women access to the particular pleasures and benefits of the game jam experience. Gorm Lai argues for the transformative potential of the game jam that “[m]any people, beginners and experts, say doing their first jam was a life changing experience" (Lai, cited in Batchelor 2017, online). I sought to make this transformative experience available to women aspiring to a role within the broader games industry.

The research element of the project at that time was to test several assumptions:

1. That an all-female game jam could open up the format to women who might not consider attending a mixed group jam. 
2. That by removing some of the financial, practical and cultural barriers to participation would foster high levels of demand for such an event.

3. That participation in a well-supported, high energy and fast-moving development event would facilitate community and empowerment amongst the women.

4. That such an event would provide an environment in which women could recognise and develop their own talents and those of other women.

5. That it would provide a potential gateway or threshold event/activity to further creative participation in games.

6. That it would provide a mechanism through which relationships could be formed, alliances build and networks established.

\begin{abstract}
This was set within a context in which industry and advocacy group reports and academic research continued to demonstrate the lack of equity in women's access to key creative and technological roles within the games industry and at a time when Jo Twist could assert that "only $7 \%$ of developers are actually female in this country" (XX Game Jam, 2012). Ordinarily wary of single gender events, Jo Twist brought UKIE on board to support the event and provided publicity and access to different potential communities of support for the activity. She framed UKIE's support for wider diversity as follows:
\end{abstract}

\footnotetext{
"We want a diversity of workforce, because when you have lots of people, with different stories to tell, with different experiences, and they bring them to a creative product, you get far more diversity of games made. Which in turn encourages more people to play games, because
} 
we're a diverse society." (Jo Twist XX Game Jam October 26, 2012, Mind Candy, Shoreditch. )

\begin{abstract}
Game jams are by their nature intense - an arbitrary and highly pressurized time frame is applied, and strict constraints and delineated affordances are established and imposed. The play-like but highly competitive nature of the game jam environment allows certain skills and aptitudes to surface and be showcased. They provide a context in which new ideas can be posited in prototype form - extending existing ideas, possibilities and providing new creative resources for the participants when returning to their everyday environments.
\end{abstract}

Global Game Jam make this appeal to skilled/unskilled/novice/expert explicit on their website:
"Although having computer skills is helpful, experience is not necessary.
Designers, developers, artists and anyone is welcome to try their hand at making a game during the GGJ. Even if you have no experience at all, you can still participate by contributing ideas, playtesting, and giving moral support to your team. You could work on a non-digital game, and then there's no need for code!" (https://globalgamejam.org/about)

\begin{abstract}
The event was scheduled to coincide with Ada Lovelace Day activities across the country, particularly London where a series of talks, conferences and workshops celebrating women's achievements and participation in science and technology were
\end{abstract}


scheduled. In 2012 this coincided with the London Games Festival. As soon as the event was conceived and marketed (largely via informal networks and social media) it received high profile press coverage and within 8 days all of the spaces were taken.

The event involved 24 women who participated over 24 hours, an intentionally lessdemanding time frame, and we were granted the use of the colourful Mind Candy offices in the creative hub of Shoreditch. The theme was Clockwork and this captured the imagination of the participating group of women immediately. The 24 women swiftly aligned themselves into 5 groups and proceeded to work energetically and collaboratively to produce their games from Friday evening at $6 \mathrm{pm}$ to $6 \mathrm{pm}$ on Saturday. The judges then played the games and interviewed the teams before making their evaluations and determinations. The event concluded with a prize-giving event. ${ }^{9}$

As part of our intentionally inclusive approach to the redesign of the game jam format we had made some funding available to support transportation, accommodation and childcare costs which was received very positively by participants and potential participants. We also had enough funding to avoid the usual pizzas and beer approach to jam catering, and were able to provide a range of nutritious meals and snacks throughout the event. It was clear that we could have more than doubled our numbers for this event as our event coordinator and leading woman in games, Debbie Rawlings reported: "I've had so many requests to go on a waiting list, or to tell them when the next event is. I've got about 40

\footnotetext{
${ }^{9}$ Jo Twist from UKIE, Tomas Rawlings from Auroch Digital, and Martha Henson from Wellcome were the judges. The prizes were a neat toolkit and some decorative paper.
} 
names now, ready to sign up for the next one, as soon as we can make that happen." $\left(\operatorname{INTD} 31^{10}\right)$

The research methodology used to document the event was a combination of surveys, qualitative interviews, guided discussions, close observation supported by video ${ }^{11}$. and photographs, pre-event questionnaires and post-event evaluation activity. A critical aspect of the work which situates it within a feminist action research mode was the invitation to all the attendees to engage as fellow researchers with direct and meaningful expertise relevant to the project and its outcomes. The interviews and guided discussions took place throughout the 24 hours and therefore had an influence on ongoing informal conversations taking place across the event - for instance, the framing of the event as explicitly feminist provoked a great deal of informal discussion amongst the participants about their experiences and perspectives, and these informal discussions set a relaxed tone for the more formal structured research and documentation interviews. The level of reflexivity and the quality of the shared insights and experiences increased as time progressed and the intensity and enforced intimacy of the game jam format took hold, which contributed to the jammer's behaviours and sense of belonging to a community.

It is the rule-bound playfulness that provides the valuable system that is the 'game jam' in

\footnotetext{
${ }^{10}$ As noted above there were a number of distinct research formats used for capturing participant responses - INT refers to structured in person interviews and for the most part unless they are part of our core team these are anonymised and SM refers to the responses gathered via Survey Monkey both before and after.

${ }^{11}$ A documentary filmmaker recorded a significant amount of the activity and all participants were interviewed over the course of the jam. This footage was also edited to create short film of the project: https://vimeo.com/61886636 XXGame Jam 2012
} 
which temporary differences and real-world problems can be marked off for a special time and place of playful creative design practice. As noted above, all game jams share this playful temporary suspension within a tightly rule bound structure and enjoy the bracketing off of differences - the all-female game jam however adds an 'other world' utopian dimension by entirely removing the normal gender ratios, roles and norms. At least part of our intention in the construction and delivery of these spaces for the practices of game design, development, planning, coding, drawing and producing is that the participants will engage in behaviours 'as if' they were skilled practitioners in this domain and 'as if' there were no barriers to their occupation of these subjectivities. Their participation can be seen as a hopeful performance or a ludic self-production - played at during the event.

In interviews, participants describe signing up as a leap of faith or a risk - "I wasn't sure I had anything to offer" "I didn’t think my skills would be relevant" "I was worried because I don't know any code" "I am really glad I took the risk of signing up" [SM $3,5,9]$. The intensity of the context set by this format brings with it specific affordances, as these embarrassments, self doubts, and feelings of inadequacy are swiftly overshadowed by the force of the game jam rule set and play world. The constraints and affordances provide an unnatural but forceful energy that fuels their creativity, confidence and drive.

The provision of these female-only spaces sets up a false but necessary condition for the participants to 'become' these creative subjects. As organiser, researcher, and facilitator 
in these environments it was easy to notice the energies shift in the room, the moments when the 'strangers' form a team with shared vision and shared goals and an aura of confidence takes over from the hesitancy that initially prevails. Responding to a question about the value of these events, the following is a particularly illustrative example of participant reflexivity about the power of an all-female game jam:

\author{
I think a large part of it is the support, and knowing that we can get \\ together and do these events. Although this is my first game jam, I \\ know that I've been talking to a lot of people here and they feel that - I \\ don't know whether due to sexism and the fact that women are often the \\ minority at events like this - it's very easy to get shut down towards \\ what contribution you can make. I think that this event's obviously \\ beneficial, so that we can really come at it at an equal basis and really \\ see what we can do without that sexism getting in the way of creating \\ games, doing what we love. (INTE)
}

The participants clearly experienced a shift in their perceptions of their own skills and contributions over the course of the event. The pre-entry survey and barriers to entry questionnaire elicited frequent repetition of the same terminology of self-doubt, lack of ability, low technical skills and an apprehension regarding the intensity of the jam experience. The sentiment of 'intimidation' featured frequently in these responses - a rich and illustrative example is: 
I never realised how much self-imposed pressure I felt before this jam like, I've always felt like I had to prove myself just to be viewed as equal. That made regular jams intimidating, especially since I have no real experience. (SM7)

This language shifted in the interviews that took place during the event and the postevent evaluation to terms such as 'confidence', 'comfort' and 'inspiration'. One participant sums up the transformative effects of their participation which was reflected in many of the responses:

It's inspirational to see how many women there are in dev roles in the industry. I met some very talented women -great for networking. It has given me the confidence in my skills to go to further game jams - and I will do this - I had an awesome day! (SM3)

A few participants blogged about their experience after the event and engaged in a wider discussion of the role of these events more generally.

http://hollymakesgames.blogspot.co.uk/2012/11/xx-game-jam.html "being a girl in game development can be freaking lonely." So whether you agree with events like this or not, that's your choice. But I like to think that everyone there came away feeling accepted, inspired and had a great time with lots of laughs. I'm sorry if that offends anyone, but I'm also not going to apologise for my having a good time making a ridiculous game, in a team with a ridiculous name and wearing a ridiculous woolly panda hat while I did it!" 
The participant is responding to some commentary that had occurred in response to the press coverage that offered the challenge that an all-female games event is segregationist and problematic. (see blogpost referenced above) Another XX Game Jam participant responds to the blogpost with the following:

I was beginning to get dragged down by the same old crowd who usually crawl out of the woodwork whenever something like this happens, crying "but we don't have all-male game jams! You're segregating yourselves!"'”

She continued:

"Sure, in a wider context this was a means to (hopefully) a more inclusive ends for all people around the games industry, but it was also great fun - and certainly the most solid learning experience I've ever put myself through! (my emphasis)

This shift between personal empowerment and a recognition of the wider context within which the participants will be operating is a key feature of a large proportion of the discussion materials, interviews and survey feedback. The participants were fully aware of this wider context and recognised the challenges they would be likely to face if pursuing careers within the industry.

For the intentional feminist impact of this event to be meaningful there is an assumption of the durability and non-ephemerality of the actions, agencies, affects evidenced during the high intensity but short lived 'jam' environment. I describe this assumption as 
founded on this future-oriented affect of hopefulness and a pragmatic (and resilient) optimism. The force of the utopian dimension has this potential to spill over in to a continued relation with the other participants (once strangers), now fellow veterans of a highly charged, competitive, challenging but also pleasurable virtual and material experience. These are temporary playful affective communities, and the feminist intentions underlying the construction of these spaces depends upon a hopeful belief in the transferability and potential legacy of these moments. It is hoped that these events provide the images, feelings, stories that can be returned to and 'played over' in their imaginations and out loud to their peers so as to provide strength and sustenance to counter negativity, invisibility and exclusionary practices encountered elsewhere.

The establishment of these events need to be read within the macro context of not just the national but also the global games industry, wider games culture and the dispiriting evidence of women's lack of participation and negative representation within the industry; the systematic abuse many have experienced as players, makers or commentators in the sector. Any activity developed to support women's participation in this field does so in recognition of these unpalatable truths about the current 'state of play' within the sector. Between the two game jams in 2012 and 2016 there was also the toxic cultural slurry that is /was \#gamergate, a controversy clearly impacting upon how the industry and wider game culture is perceived by any aspiring participant in the field.

To counter this I would cite the fact that an overwhelming majority of the XX Games Jam 2012 have gone on to flourish within games or games related industries. Many of 
them are working for critically-minded and innovative independent game studios with an eye to transformative or experimental practices. Four of the participants have in different ways set up initiatives to support other women - two of them forming an alliance to form LadyCade (www.ladycade.org) and another two setting up a network and series of workshops to support women in games in Bristol. (https://grrrlgames.wordpress.com).

\section{Section 5: XX+ Game Jam 2016 - Four Years Later..}

In 2016, drawing on new funding available through ReFIG, I set out to stage a minimum of 5 all-female events in the UK. The events were geographically dispersed: one took place in Leamington Spa, once a major cluster of small and independent games companies, many of which then merged leaving a long tail of much-smaller microbusinesses and lone practitioners. Arch Creatives was an initiative set up to provide resources for this constellation of talent through the provision of highly affordable desk space, networking, workshops and business support (See Crogan, P., (2018) this issue). Run by Alex Darby, this is an environment that seeks to be visibly inclusive and Alex leapt at the opportunity to be involved in the delivery of an all-female game jam in that space.

\footnotetext{
Another site was Brighton, UK, which is a key 'hot spot' outside of London for small and medium sized games companies. As a vibrant creative city it also features a relatively lively range of grass roots, community and activist groups focussed on supporting women's access to the creative industries.
} 
Bristol, UK has a similar clustering of games companies, creative start-ups and small organisations developing innovative and speculative technologies. Bristol is also the site of an initiative supporting women's access to games that was launched by an alumnus from the previous 2012 event - Constance Fleuriot. (https://grrrlgames.wordpress.com)

In London the two events took place in quite different environments - although both university premises one was more informal/creative lab space (SouthBank University) and the other a beautiful old academic room with wood panelling and the remnants of a library furnishing the shelves around the room (King's College London).

As briefly outlined above, this second set of interventions was intended to draw on the learning from the first event in 2012 and to revisit the methodology of an all-female game jam in general as an interventionist/activist methodology for providing support for women in game. The five venues also extended the sense of a wider 'community of practice' for the participants and this was supported by a social media for the exchange of game designs, prototypes, photographs and further resources both before and after the event.

\begin{abstract}
Along the way there were some surprising difficulties, as we had some very negative feedback from potential partners regarding the naming of the event. There was a sense that this name could be seen as essentialist and exclusionary given the reference to the XX chromosomes. This was something that had come up in 2012 as well and we had
\end{abstract}


worked hard to ensure that the call for participation signaled the inclusivity of the event and our wider political agenda as organisers. The title is intended to be a playful allusion to the indeterminacy of sex and the determining nature of gender in women's participation in the games industry. In 2016 we added the + to reflect the changing context within which these events were taking place (LGBTQ events in the UK had also for a while been using the + sign). The call for participation signaled the inclusive nature of the proposed events:

'Calling all women who like games - have you ever wanted to make one? ReFIGuk are delighted to announce the $\mathbf{X X}+$ games jam, 24 hours of fun and games design for women, transgender and non-binary people funded by ReFIG. UK sites will be running in Brighton, Bristol, Leamington Spa \& London.”

One respondent commented on the positive aspects of the 'branding' of the event as women-only in such a way:

"really helpful to have this branding. Discouraging to see that there are not many women in the games industry. ..this event helped me to connect with other women who share interests and skills." (CK)

\begin{abstract}
The events (in 2012 and 2016) have been reflected on very positively by participants for their inclusivity and for the diversity of the groups in terms of race, class, background, life experience, ambitions and age and also specifically for the extent to which the environment felt safer and welcoming.
\end{abstract}


" The value is to encourage women to work together and develop games, without fear of being treated differently on account of our gender (being pushed out of discussions, being talked down to, etc). During the jam, our team discussed how hard it is to be a minority working on a group project, and it's easy to appreciate how these behaviours can be discouraging for a young female games developer (even if they aren't intentional by anyone). Also, it's excellent that this provides a safe space for transgender developers to work.” (BR1)

\begin{abstract}
Again, note the extent to which (as in 2012) these events foster a dialogue of shared experience, and a shared analysis of modes of exclusion. The framing of the events within the wider structures of the ReFIG initiative and a feminist critique of the games industry in general had a clear 'consciousness raising' effect within the participant discussions and responses. The self-reflexivity that this framing encouraged in the women is evident in all their interview and survey responses.
\end{abstract}

Timed once again to coincide with the Ada Lovelace celebrations in the UK and taking advantage of the King's College London Arts \& Humanities Play festival, we had over 150 applicants for the event from as far afield as Brussels, Paris, Germany, Austria and Switzerland. $^{12}$

\footnotetext{
${ }^{12}$ We were really lucky to have such excellent partners in different locations providing support. King's Play Festival, Pervasive Media Studio, Arch Creatives for Space \& facility \& Unity and Media Molecule for tech and mentoring support.
} 
We had deliberately chosen a political theme-borders. We also prompted critical dialogue with follow up details on the theme - borders between peoples, between genders, between cultures, between nations. Many responded to this political context particularly in Brighton and Bristol. The participants explored themes of migration, difference, mental health, safety, freedom of movement through their game projects, which included board games. Across the whole group there were only 5 women who had participated in a game jam before and a similarly small number had ever experienced a woman-only event.

In the feedback from our respondents and through observation it becomes clear that the atmosphere of the jams is either noteworthy or of significant importance. Respondents across the sites commented upon the feel of the room, the space, the mood and behaviour of the organisers, and helpers as well as other staff, supporters, volunteers, judges, and visitors in setting this atmosphere.

In industries oversaturated with men it is nice to have safe space and an environment where you can contribute and not feel intimidated and not feel like you are in the wrong space. (MTK)

\begin{abstract}
Others described the environments as 'comfortable', 'warm', 'inclusive', 'supportive', 'nurturing', 'diverse', 'responsive' - reflecting here the impact of the affective labour of the organisers and facilitators in setting the tone and fostering this supportive environment and collaborative ethos even in the context of the overarching competitive nature of the format.
\end{abstract}


Some of the responses reflected very clearly the UK context within which these events took place - a context where there is not the same level of visibility for women's networking events and informal learning activity related to the games industry as there are in other countries within the REFIG partnership.

I had no idea what a games jam was three weeks ago. Even so, a huge reason why I signed up is because it was women only - frankly, I would have found a mixed-gender event off-putting (BL4)

In Chella Ramanan's report/summary of the Bristol event you see many of the tropes that were present in the feedback across the country -

Events like $x x+$ game jam are important because they help create an environment that's free from the unconscious gender bias many of us have. [...] An all-female/trans event is important for that first step into making games before joining a mixed gender jam. I had an extremely positive experience. http://www.gameindustry.com/editorials/eurofiles/went-xx-game-jamwrote-game/ (my emphasis)

\begin{abstract}
Chella's feedback and reflections negotiate this individual transformation and the wider impact of these events on the industry in general, whilst also clearly signaling the critical importance of female only spaces and their potential as a transformational event.
\end{abstract}


Another respondent from a different location elaborates on the value and empowering nature of these events in her interview:

“allowing women to have a space within game making - a very male dominated space - give them the voice that they would otherwise find challenging to express in a space that is shared with men as well"

And another:

[we are] conditioned to be quiet and not to try things. This is a great safe space. An opportunity to explore what it is to make a game, and share a game." (GBK)

Chella's rich post-event reflexive blog entry sadly exposes the limited progress made in this terrain:

I'm excited about events like $\mathrm{XX}+$, which can help create a real shift in the games industry. There's still much to be done, in terms of class and ethnicity, as the games industry is largely white and middle class, even at all women events. That said, $\mathrm{XX}+$ is a step in the right direction for reaching out to minority voices that enrich our industry and help us create different player experiences.

\footnotetext{
Most of the participants testimonies and responses to our questions made this shift between their individual experience and broader cultural needs for and value of these allfemale, inclusive and markedly/delineated 'safer spaces'. As in 2012, the participant feedback overwhelming supports a statement of the value of the event as informative, transformative and confidence building:
} 
"My knowledge of the games industry has completely changed and I would now consider this as a potential avenue for me." (ETK)

One of the respondents gave a response that resonated with both Gill's work and that of Harvey and Shepherd cited above. Asked why she had never attended a game jam before she replied: "I have never had the confidence. Never felt I had the right skillset or the 'right' to be in the space." (MBK)

As in 2012 we were able to offer some limited funding to support travel and accommodation but also discovered during the event that one of the Universities had supported the participation of 4 of their female students (paying for travel, accommodation and loaning them laptops to facilitate their engagement). The participants came from many different backgrounds in each location including these four who were students and they were all very positive about their experience and recognised the value of this event and the provision of a 'female only' environment - a ludic space in which they had a new freedom to explore their creative subjectivities.

\section{Conclusion:}

These two case studies sit within a much wider project that aims to create effective means to bring about critical transformation within the games industry and games culture (ReFIG.ca) and as such they will inform the development and instantiation of further 
such events and activities. The experimentation with the form of these interventions will of course continue within and beyond the lifetime of this project. What these two case studies have demonstrated is that the addition of an explicit (and explicitly feminist) research framework brought about a really valuable layer of self-reflexivity amongst the participants. Being explicit about the questions, the intentions, the curiosity and the genuine passionate commitment to transformation in the field of games at the outset played an important role in setting the tone and atmosphere as well as being key to helping to 'recruit' the participants to a sense of shared endeavor.

Participants were invited to consider and review their preconceptions and to consider the value of these events in addressing the barriers that they believe exist - practically, socially, culturally and personally. As a form of feminist action research, the participants were invited to consider themselves as co-researchers - reflecting upon the activity as it took place and being invited to contribute their views and ideas with the authority of their experience paramount. This authority is expressed most vividly when these participants go on to blog about their participation, or embark on their initiatives to support other women. All the contributors have helped to shape the series of follow-on events that will take place between 2018 and 2019 each of these developed in response to the participant feedback.

As I indicated at the outset, the game jam format itself is a problematic reflection in miniature of wider industrial practices around project work: intense pressure, non-stop or well in to the night working, temporally bounded and poorly compensated creative labour 
in the service of innovation within the wider industry. The format we developed over these events mitigated a number of these factors, to provide transformative, nurturing and enriching spaces of self-discovery and empowerment.

\begin{abstract}
As I have argued however, these are spaces through which empowering and creative subjectivities can be experienced and expressed. These moments of imaginative, transformative self-reinvention have the potential to provide resources for participants to remain hopeful as they encounter challenges on the treacherous pathway leading to the precarity of employment with the games sector. Many leave the session armed with a network of other women with whom and from whom they can draw strength as well as an important sense of being part of a community of practice. Feminist activity is also urgently needed from the other end of the horribly named 'pipeline' as well, in order to transform those spaces of creative production and to work from within these to create pathways of inclusion through which to engage, recruit, support and develop a more diverse talent base.
\end{abstract}

\title{
Reference List
}

Anderson, B., (2006) Becoming and being hopeful: towards a theory of affect Environment and Planning D: Society and Space 24, pages $733-752$

Banks, J., Humphreys, S. (2008) The Labor of User Co-Creators: Emergent Social Network Markets Convergence 14 (4): 401-18.

Banks, J., Deuze, M. (2009) Co-creative labour. International Journal of Cultural Studies 
12(5): 419-431

Banks, M., Milestone, K. 2011 Individualization, Gender and Cultural Work Gender, Work and Organization. 18 (1): 73 - 89

Coleman, R. (2016) A Sensory Sociology of the Future: Affect, hope and inventive methodologies The Sociological Review 60(S1) 18-39

Conor, B., Gill, R. and Taylor, S. (2015), Gender and creative labour. The Sociological Review, 63: 1-22

Cook, G., Smith, G., Thompson, T., Togelius J., Zook, A. Hackademics: A Case for Game Jams At Academic Conferences, Proceedings of the 10th International Conference on the Foundations of Digital Games

Cowan, T.L., Rault, J. (2014) The Labour of Being Studied in a Free Love Economy, Ephemera: Theory and Politics in Organization, 14 (3) 471-488

Deen (M) et al. CHI 2014, Apr 26 - May 01 2014, Toronto, ON, Canada ACM 978-14503-2474-8/14/04. http://dx.doi.org/10.1145/2559206.2559225

de Peuter, G, Dyer-Witheford, N. (2005) A playful multitude? Mobilising and countermobilising immaterial game labour. Fibreculture 5 http://five.fibreculturejournal.org/fcj024-a-playful-multitude-mobilising-and-counter-mobilising-immaterial-game-labour/ Donath, S. (2000)“The Other Economy: A Suggestion for a Distinctively Feminist Economics." Feminist Economics 6 (1): 115-23 


\begin{abstract}
Duffy, B. E., (2015) The romance of work: gender and aspirational labour in the digital culture industries. International Journal of Cultural Studies 19 (4) 441 - 457
\end{abstract}

Gill, R. (2002) Cool, Creative and Egalitarian? Exploring Gender in

Project-Based New Media Work in Europe, Information, Communication \& Society, 5(1) 70-89,

Gill, R. (2014) Academics, Cultural Workers and Critical Labour Studies Journal of Cultural Economy 7 (1) $12-30$

Goddard, W., Byrne R., Mueller, F. (2014) Playful Game Jams: Guidelines for Designed Outcomes IE2014, December 02 - 03 2014, Newcastle, NSW, Australia http://dx.doi.org/10.1145/2677758.2677778.

Guevara-Villalobos, O. (2011) Cultures of independent game production: examining the relationship between community and labour', in Think Design Play: Proceedings of the 2011 Digital Games Research Association Conference, eds. M. Copier, H. Kennedy \& A. Waern, [Online] Available at:http://www.digra.org/dl/db/11307.08157.pdf

Gregg M (2009). Learning to (love) labour: production cultures and the affective turn. Communication and Critical/Cultural Studies 6(2): 209-214

Goddard, W., Byrne, R., Mueller, F. (2014) Playful Game Jams: Guidelines for Designed Outcomes IE2014, December 02 - 03 2014, Newcastle, NSW, Australia

Harvey, A., Fisher, S. (2015) “Everyone Can Make Games!” The postfeminist context of women in digital game production, Feminist Media Studies, 15 (4), 576-592 
Harvey, A., Fisher, S. (2016) Growing pains: feminisms and intergenerationality in digital games, Feminist Media Studies, 16 (4), 648-662,

Harvey, A., Shepherd, T. (2016) When passion isn’t enough: gender, affect and credibility in digital games design International Journal of Cultural Studies 20 (5), 492508

Hesmondhalgh D. (2010) "User-Generated Content, Free Labour and the Cultural Industries." Ephemera 10 (3/4): 267-84.

Huntemann, N. (2015) No more excuses: using Twitter to challenge the symbolic annihilation of women in games. Feminist Media Studies 15(1): 164-167

Jarrett, K. (2014) The Relevance of “Women's Work": Social Reproduction and Immaterial Labor in Digital Media Television \& New Media 2014, Vol 15(1) 14-29

Jenson J, de Castell S (2013) Tipping points: marginality, misogyny, and videogames. Journal of Curriculum Theorizing 29(2): 72-85

Kuehn, K., Corrigan, T (2013) Hope Labor: The Role of Employment Prospects in Online Social Production, The Political Economy of Communication 1(1), 9-25

Lewis, H. (2012) 'Dear the internet, this is why you can't have anything nice', New Statesman, [Online] Available at:http://www.newstatesman.com/blogs/internet/2012/06/dear-internet-why-you-canthave-anything-nice 
Oksala, J. (2016) Affective Labor and Feminist Politics, Signs: Journal of Women in Culture and Society, 41 (2)

Preston, J. A., Chastine, J., O’Donnell, C., Tseng, T., \& MacIntyre, B. Game Jams:

Community, Motivations, and Learning among Jammers. International Journal of GameBased Learning, 2(3) (2012), 51-70

Ross, A. (2013). In search of the lost paycheck. In T. Scholz (Ed.), Digital labor: The internet as playground and factory (pp. 13-32). New York, NY: Routledge.

Schumacher, B. (2003). A philosophy of hope. New York, NY: Fordham University Press

Terranova, T. (2000). Free labor: Producing culture for the digital economy. Social Text, 63(18), 33-58. 